El discurso psicopatológico de la modernidad: ensayos de historia de la psiquiatría

Enric Novella

Madrid, Espanha: Catarata, 2018, 157 págs.

\title{
Por uma psiquiatria criticamente ciente de seu desenvolvimento histórico
}

For a psychiatry critically aware of its historical development

Nas últimas décadas a mente humana tem sido reconhecida como objeto fronteiriço de estudo entre diversas disciplinas, recebendo aportes conceituais desde áreas clínicas, como a psicologia, a psiquiatria e a neurologia, até contribuições filosóficas, sociológicas, antropológicas e históricas, passando por pesquisas em neurociência e outros domínios do pensamento e da cultura (Huertas, 2013). Entretanto, um campo com contribuições tão diversas corre o risco de se deparar com "reducionismos tão frequentes quanto perigosos" (p. 1). Em contraponto a esses reducionismos encontramos o livro El discurso psicopatológico de la modernidad - Ensayos de historia de la psiquiatría, do médico espanhol e historiador da psiquiatria Enric Novella.

\footnotetext{
${ }^{*}$ Universidade Estadual de Campinas - Unicamp (Campinas, SP, Brasil).
} 
Em 157 páginas o autor sustenta a tese de que as transformações históricas da subjetividade ("as pautas de relação, compreensão e atuação dos indivíduos a respeito de si mesmos", p. 26) configuram ao longo do tempo expressões clínicas muito diversas da loucura, do mal-estar e dos transtornos mentais, e mantêm uma relação constitutiva com algumas das categorias mais emblemáticas da psiquiatria atual.

Novella divide seu livro em duas partes. A primeira delas, intitulada "Locura, Ciencia y Modernidad", em seu primeiro capítulo, "La medicina mental", explora cinco grandes processos constitutivos do mundo moderno relacionados ao interesse médico pela vida psíquica: 1) a dissolução da ordem estamental do Antigo Regime e a progressiva extensão dos ideais democráticos e emancipadores das revoluções burguesas dos séculos XVIII e XIX; 2) o crescimento do individualismo e a projeção cultural de uma subjetividade capturada entre o cultivo de si mesma e alvo de um novo conjunto de discursos e práticas científicas; 3 ) a progressiva medicalização do psiquismo por efeito de um amplo e complexo processo de secularização e naturalização da alma/consciência; 4) o novo papel outorgado à medicina como instância normativa e sua crescente intervenção na regulação dos assuntos humanos; e 5) a ampla percepção de risco de uma regressão civilizatória devido à vida moderna e à erosão dos valores avalizados pela tradição.

No segundo capítulo, "La clínica de la subjetividad", o autor busca demonstrar como o projeto de capturar, descrever e catalogar experiências subjetivas foi não só um dos fatores mais relevantes para a conformação histórica da psicopatologia descritiva, mas também o acontecimento verdadeiramente fundacional da psiquiatria como saber específico. Nesse sentido, ele analisa as origens e os problemas da semiologia psiquiátrica na obra de Philippe Pinel e detalha alguns dos recursos empregados pelos seus sucessores com a finalidade de se aproximar do mundo interno dos pacientes e descobrir os recônditos de sua intimidade. Novella aponta como o projeto do alienismo, que se inscrevia epistemologicamente na busca da compreensão e construção do conhecimento pela observação/visão, "em sua ambição de "visibilizar o invisível' [a subjetividade] e elaborar uma ciência empírica dos fenômenos psíquicos, se viu impelido em um determinado momento histórico a praticar a escuta" (p. 60).

No terceiro capítulo, "La mirada psicopatológica", o autor examina o processo de expansão da perspectiva psicopatológica ao longo das primeiras décadas do século XIX, muito antes de existirem as classificações diagnósticas psiquiátricas contemporâneas (Zorzanelli, Bezerra Jr., \& Costa, 2015), 
e explicita algumas das principais discussões e controvérsias suscitadas nessa época pela aplicação, por parte de alguns psiquiatras, da própria psicopatologia como ferramenta de análise histórica, diagnóstico social e crítica cultural. Como exemplo, toma o debate científico, polêmico já naquele tempo, em torno da localização dos fenômenos alucinatórios e do suicídio no campo da normalidade ou da patologia, fenômenos que eram vistos por autores diferentes ora como questões médicas, ora como fruto de uma cultura que, assim como hoje, era considerada por muitos responsável pelo aumento da ocorrência de transtornos e padecimentos psíquicos.

Os ensaios reunidos na segunda parte do livro, intitulada "Las heridas del sujeto", examinam as principais coordenadas epistemológicas e socioculturais que situam a constituição de alguns dos transtornos mentais particularmente prevalentes e representativos em nossa época. No quarto capítulo, "Individualidad", Novella explora o antigo legado da melancolia, apontando como essa condição clínica, especialmente durante o renascimento e o barroco, carregava consigo compensações individuais para aqueles que a apresentavam, especialmente a intensificação do pensar e o contato íntimo com o conhecimento, mas também riscos coletivos, como a devassidão, a paralisia e o ócio, 172 desvalorizados em uma sociedade capitalista em florescimento por se oporem ao trabalho. O autor apresenta, a partir daí, a atual pandemia depressiva como uma consequência do aprofundamento, radicalização e generalização de uma cultura da individualidade que, reservada inicialmente a pensadores, artistas e literatos, acabou se estendendo a boa parte da população.

No quinto capítulo, "Reflexividad", Novella apresenta o desenvolvimento do conceito clínico de esquizofrenia e expõe linhas de compreensão da experiência esquizofrênica especialmente sob a óptica da psicopatologia de inspiração fenomenológica. A partir daí relaciona os próprios fenômenos psicopatológicos da esquizofrenia com os fenômenos socioculturais modernos e pós-modernos de objetificação dos conteúdos da consciência, tendência à reflexividade (que "leva a consciência a caminhar ... sempre um passo antes de si mesma ... não vendo o mundo, mas observando a percepção que dele tem”, p. 123) e cisão ou fragmentação da consciência. Para o autor, a esquizofrenia é o "testemunho mais dramático de uma cultura que nos converte todos em possuidores, informantes e manipuladores de um 'eu', e que nos leva a nos relacionar com o mundo, os demais e nós mesmos do parapeito de uma reflexividade que nos distancia da espontaneidade, do imediato e ... até da vida. Uma cultura que, como não poderia ser de outra maneira, leva assim em seu núcleo o gérmen e o fundamento de sua própria alienação" (p. 124). 
No sexto e último capítulo, "Identidad", o autor delineia a trajetória dos "estados fronteiriços" na história da psiquiatria clínica, enfatizando a centralidade da patologia da identidade na gênese do transtorno de personalidade borderline. Novella avança majoritariamente em direção à modernidade tardia, recorrendo a análises e semiologias do mundo contemporâneo que tentam dar conta da problemática da identidade pessoal, abordando desde as mudanças tecnológicas, o pluralismo de valores, a abolição da consciência histórica, o capitalismo pós-industrial, o instrumentalismo da razão, a burocratização da existência, entre outros.

O autor não só articula o desenvolvimento histórico-cultural que permitiu a elaboração, a visibilização e a ampliação da ocorrência desses transtornos, mas também demonstra, com consistência, como tais categorias clínicas desempenham a função de metáforas diagnósticas da modernidade, sendo consequência e ao mesmo tempo índices dos desdobramentos culturais em torno da individualidade, da reflexividade e da identidade ao longo da história. O livro passa a ser, portanto, obra obrigatória para aqueles que reconhecem a importância de uma história da psiquiatria que interpele o passado para pensar o presente e para propiciar práticas atuais e futuras suficientemente fundadas (Huertas, 2013).

\section{Referências}

Huertas, R. (2013). Another history for another Psychiatry: The patient's view. Culture \& History Digital Journal, 2(1).

Zorzanelli, R., Bezerra, J. R.B., \& Costa, J. F. (Orgs.). (2015). A criação de diagnósticos na psiquiatria contemporânea. Rio de Janeiro, RJ: Garamond.

Citação/Citation: Gonçalves, A.M. N. (2019, março). Por uma psiquiatria criticamente ciente de seu desenvolvimento histórico. Resenha do livro El discurso psicopatológico de la modernidad. Ensayos de historia de la psiquiatría. Revista Latinoamericana de Psicopatologia Fundamental, 22(1), 170-174. http://dx.doi.org/10.1590/1415-4714.2018v22n1p170.11.

Editores do artigo/Editors: Profa. Dra. Marta Regina de Leão D’Agord 
Submetido/Submitted: 26.10.2018 / 10.261.2018 Aceito/Accepted: 21.1 .2019 / 1.21.2019

Copyright: (C) 2009 Associação Universitária de Pesquisa em Psicopatologia Fundamental/ University Association for Research in Fundamental Psychopathology. Este é um artigo de livre acesso, que permite uso irrestrito, distribuição e reprodução em qualquer meio, desde que o autor e a fonte sejam citados / This is an open-access article, which permits unrestricted use, distribution, and reproduction in any medium, provided the original authors and sources are credited.

\section{Arthur Maciel Nunes Gonçalves}

Psiquiatra; Doutor em Ciências Médicas pela Universidade Estadual de Campinas - Unicamp (Campinas, SP, Br).

Av. Domingos de Morais, 2777/133

04035-001 São Paulo, SP, Br

https://orcid.org/0000-0001-8299-5379

arthurmaciel@gmail.com

This is an open-access article, which permits unrestricted use, distribution,

(cc) BY-NC and reproduction in any medium for non-commercial purposes provided the original authors and sources are credited. 